Regina Madalozzo

Instituto de Ensino Superior, São Paulo, SP, Brasil

Merike Blofield

University of Miami, Miami, Flórida, EUA

\title{
Como famílias de baixa renda em São Paulo conciliam trabalho e família?
}

Resumo: Embora a participação das mulheres no mercado de trabalho tenha aumentado, a comparação entre a carga de responsabilidade familiar entre homens e mulheres e seus diferentes impactos na vida pessoal e profissional de pais e mães ainda é bastante desigual. Partindo de uma pesquisa representativa de 700 mães e pais com crianças pequenas e residentes em bairros de baixa renda em São Paulo, esse artigo analisa a diferença de gênero no mercado de trabalho, sua relação com as responsabilidades familiares e acesso a creches e préescolas para seus filhos nesta classe social. A análise desses dados permite concluir que os impactos do conflito trabalho-família são desproporcionais para as mães, independente de preferirem ou não permanecer no mercado de trabalho. Políticas de coparticipação do Estado e dos pais no cuidado são indicadas para redução desse conflito.

Palavras-chave: família; mercado de trabalho; gênero; famílias de baixa renda

\section{(c) (i)}

Esta obra está sob licença Creative Commons.

' Por gênero entende-se "qualquer agrupamento de indivíduos, objetos, idéias, que tenham caracteres comuns" (FERREIRA, 1986, p. 844). Entretanto, mais do que uma definição de grupamentos, a definição de gênero também inclui as diferenças culturais, de relação de poder, entre outras que definem as relações de feminino, masculino e transgênero, e, não, somente, de sexo biológico, como homem

\section{Introdução}

As questões de gênero' na participação da força de trabalho, bem como o papel das relações culturais e de poder que perpetuam a diferença entre homens e mulheres, até mesmo na questão de trabalhos domésticos e de cuidado, são discutidas por diversas áreas de estudo. $O$ foco na economia é, geralmente, direcionado para prêmios no salário para os homens que têm filhos e penalidade para as mulheres que os têm. Na sociologia, as escolhas entre trabalho remunerado ou não (incluindo as esferas de cuidado) colocam em disputa as questões de preferências pessoais em contraponto com as restrições que mantêm as mulheres como responsáveis pelo cuidado na família. Em 
e mulher. Uma discussão mais profunda sobre esse assunto pode ser encontrada em Guedes (1995). ambas as disciplinas, o impacto de políticas públicas no comportamento das pessoas é discutido. Nesse sentido, uma maior disponibilidade de creches e pré-escolas (com o objetivo de permitir uma escolha profissional para as mulheres que assim o quiserem) pode ter um impacto bastante relevante nas diferenças entre homens e mulheres. Em um país com tamanhas desigualdades sociais e de gênero (Waldemir ROSA, 2009), focar na questão das responsabilidades familiares e seus efeitos no mercado de trabalho é muito relevante. A literatura internacional foca majoritariamente em estudos sobre países industrializados. Esse estudo, em direção oposta, analisa o caso do Brasil, mais especificamente da cidade de São Paulo, com uma pesquisa inédita com 700 indivíduos (pais e mães). A seleção amostral foi direcionada para a população de renda mais baixa (classes C, D e E), pois são para essas famílias que as oportunidades são menores e menos frequentes e, portanto, as tensões entre trabalho e família tendem a ser mais elevadas (Jody HEYMANN, 2006; Bila SORJ, 2013). Com base em um conjunto de dados original, que consiste em um levantamento representativo de 700 pais de crianças com menos de 6 anos de idade em bairros de baixa renda de São Paulo, este estudo avalia a diferença de gênero no mercado de trabalho, sua relação com as responsabilidades familiares e acesso a creches e pré-escolas para seus filhos nesta classe social. A análise desses dados permite concluir que os impactos do conflito trabalho-família são desproporcionais para as mães, cuja participação no mercado de trabalho sofre com a falta de acesso a alternativas com relação a creches e pré-escolas e direta discriminação por parte dos empregadores. Também é possível perceber que, enquanto os pais que moram com seus filhos estão muito envolvidos em cuidar dessas crianças, a maioria dos pais não residentes não apoia seus filhos financeiramente e de forma regular, e menos de $5 \%$ deles participam no cuidado direto de seus filhos pelo menos uma vez pela semana. A partir dessas conclusões, entende-se que uma maior responsabilização por parte dos pais e uma corresponsabilização por parte do estado são fatores essenciais para o aumento do bem-estar das mães e das crianças. A promoção da igualdade de gêneros, além de reduzir a pobreza e desigualdade, faria com que o capital humano no Brasil fosse mais bem utilizado.

O presente artigo conta com 5 (cinco) seções. A seção 2 (dois) apresenta o referencial teórico que baseou a construção do questionário e motivou a pesquisa conduzida. A seção seguinte apresenta a criação e condução da pesquisa de campo. A seção 4 (quatro) apresenta a descrição dos resultados encontrados na pesquisa e os 
compara com as bases do referencial teórico. Por fim, a seção 5 (cinco) conclui o estudo.

\section{Referencial teórico: o hiato de gênero}

É bastante conhecido o resultado de que, enquanto a paternidade tende a ser boa para a carreira dos homens, a maternidade prejudica a carreira das mulheres (Michelle BUDIG; Paula ENGLAND, 2009; Kimberly KELLY; Linda GRANT, 2012; Markus GANGLE; Andrea ZIEFLE, 2009; Alexandra KILLEWALD, 2013). Isso funciona nos dois sentidos: os empregadores tendem a preferir pais sobre as mães e, por uma variedade de fatores, muitas mulheres saem da força de trabalho ou reduzem suas horas de trabalho, especialmente se elas têm um parceiro estável que participa da força de trabalho. De fato, um estudo usando amostras de áreas metropolitanas no Brasil constatou que a presença de crianças no domicílio reduz a inatividade de trabalho para os homens, mas aumenta a mesma para as mulheres (Pedro Rodrigues DE OLIVEIRA; Luiz Guilherme SCORZAFAVE; Elaine Toldo PAZELLO, 2009).

Duas significativas teorias sociológicas apresentam diferentes interpretações a respeito da redução da participação de mães no mercado de trabalho: a teoria das preferências e a teoria do papel do conflito. A primeira afirma que as mães preferem ficar em casa, com seus filhos, enquanto a segunda coloca seu foco nas restrições: as mães têm a responsabilidade do cuidado para com as crianças, independente de suas preferências pessoais, fazendo com que a presença de crianças no domicílio seja mais uma força impeditiva do trabalho remunerado, algo que é "virtualmente ausente da vida dos homens" (Michèle Ernst STÄHLI; René Levy LE GOFF; Eric WIDMER, 2009).

No Brasil, as taxas de participação das mulheres na força de trabalho aumentaram de pouco menos de $50 \%$, em 1990, para 59,4\%, em 2013 (Banco Mundial), e para $72 \%$ para as mulheres em idade fértil (UNDP/ILO, 2009; IBGE, 2013). Ao mesmo tempo, enquanto a distribuição de renda tornou-se um pouco menos desigual ao longo da última década (Marcelo Cortes NERI, 2011 ), o Brasil continua sendo um dos países com maior desigualdade social no mundo (João ARNOLD; Jen JALLES, 2014), com um índice de Gini de 0,55 em comparação com 0,30 para a União Europeia (Banco Mundial).

Segundo dados da PNAD 2013 (IBGE, 2013), a taxa de ocupação das mulheres brasileiras em idade fértil a partir do quintil mais elevado é de $80 \%$, enquanto ela se revela de apenas $36 \%$ para o quintil de menor renda. Os valores correspondentes para o caso dos homens são de $91 \%$ e 
$73 \%$. Mulheres de alta renda, bem como homens de baixa renda, têm mais do que o dobro da probabilidade de estar na força de trabalho - e empregados - do que as mulheres de baixa renda, refletindo a interação entre classes sociais e desigualdades de gênero.

O fator-chave para a diferença entre os gêneros é a desigual divisão do trabalho entre homens e mulheres. Concomitante a isso, o fator mais importante na dramática diferença entre classes no emprego das mulheres diz respeito à relativa facilidade com a qual as famílias de alta renda terceirizam cuidados e trabalho doméstico ao setor privado (Helena HIRATA; Nadya Araujo GUIMARÃES, 2012). Com mais de seis milhões, ou $16 \%$ da força de trabalho feminina urbana, o Brasil tem o maior número de mulheres empregadas no serviço doméstico do que qualquer país do mundo (DIEESE, 2013). De fato, o serviço doméstico é o modo domi-nante para resolução dos conflitos com os cuidados e sua prevalência no Brasil (bem como no resto da América Latina) está diretamente ligada às desigualdades socioeconômicas (Merike BLOFIELD, 2012). Como resultado, as profissionais mulheres - especialmente o coorte mais jovem, onde muitas delas têm maior probabilidade de ter ensino superior completo do que os homens da mesma faixa etária - têm sido relativamente bem-sucedidas em entrar no mercado de trabalho e alcançar posições mais altas hierarquicamente.

E quanto à grande maioria das brasileiras que não tem essa opção, e muitas das quais trabalham no serviço doméstico elas mesmas? Conforme dados da PNAD 2013 (IBGE, 2013), a diferença de emprego entre homens e mulheres no quintil de renda mais baixa, de $49 \%$, é, também, grande. Essa pesquisa examina como os conflitos entre trabalho e família são resolvidos nesses quintis de renda. Conclui-se que, entre as mães, a falta de acesso a creches e pré-escolas, bem como a discriminação por parte dos empregadores, reduz a possibilidade dessas mulheres em participar do mercado de trabalho, causando ainda mais estresse para essas famílias. Pais que residem com seus filhos, por outro lado, têm um ajuste mais suave para equilibrar as demandas de trabalho e as familiares. A seguir, será descrita a metodologia e, em seguida, serão apresentadas as estatísticas descritivas do resultado da pesquisa.

\section{Construção da pesquisa}

A presente pesquisa, denominada "Conciliando trabalho e família", teve foco em pais e mães de crianças com menos de seis anos de idade (abaixo da idade escolar obrigatória em 2012), pois é neste grupo que os conflitos entre trabalho remunerado e não remunerado são mais 
${ }^{2}$ Além do critério renda, utilizouse uma extratificação dos bairros via Critério Brasil de classe social da ABEP - Associação Brasileira das Empresas de Pesquisa - para efetivamente, se ter acesso mais focado a famílias das classes C$\mathrm{D}$ e E.

${ }^{3}$ Para os grupos focais, contratouse a empresa Ética, Pesquisa de Mercado e Opinião. Já a pesquisa quantitativa teve seu campo conduzido pela empresa Rada Representações e Pesquisas.
${ }^{4}$ Antes de ser aplicado em campo, o questionário foi testado em um piloto (pré-teste) nos dias 10 e 11 de agosto de 2012. graves, uma vez que as crianças necessitam de cuidados mais intensivos nessa faixa etária e os pais de baixa renda têm menos recursos financeiros para terceirizar esse cuidado. A pesquisa permitiu a formação de uma base de dados original com 700 respondentes entre mães e pais que residem em bairros de baixa renda da cidade de São Paulo e que tinham, ao menos, uma criança com menos de 6 anos de idade vivendo no domicílio. A definição do critério de baixa renda foi estabelecida para bairros com uma renda familiar média de $\mathrm{R} \$ 1.500$ mensais ou menos. ${ }^{2} \mathrm{~A}$ fase de entrevistas foi realizada entre agosto e outubro de 2012 e teve financiamento da FAPESP (Fundação de Apoio à Pesquisa do Estado de São Paulo).

Para a confecção do questionário e antes mesmo da definição dos bairros que fariam parte da amostra a ser coletada, a pesquisa contou com quatro grupos focais. Dois grupos de mães com, ao menos, um filho menor de 6 anos e um grupo com pais, também com crianças nessa faixa etária. Os grupos focais se reuniram no mês de abril de 2012 e as entrevistas foram conduzidas por uma mesma especialista para os quatro grupos: ${ }^{3}$ dois com mulheres que tinham um companheiro residindo em seu domicílio, um com mulheres solteiras, separadas, divorciadas ou viúvas, e um grupo com homens que residiam com uma companheira. Essas entrevistas em grupos focais tinham duração de 2 horas, aproximadamente, e o roteiro prévio incluía a discussão dos principais tópicos da pesquisa: como é a vida de uma mãe/ pai com filhos pequenos, a questão da escola e vagas em escolas públicas, a distribuição de responsabilidades dentro da família (trabalho doméstico, trabalho remunerado e cuidado com crianças), desejos para melhorar a qualidade de vida, conflitos com empregadores e análise geral de políticas públicas ou serviços públicos (como transporte e saúde, por exemplo).

A partir dos resultados coletados nos grupos focais, montou-se um questionário a ser aplicado em campo. ${ }^{4}$ Esse questionário contava com 65 questões divididas nos seguintes blocos:

- Questões sobre composição familiar e renda.

- Características demográficas do entrevistado (mãe e pai, um em cada momento do tempo).

- Informações sobre todos os filhos, independente da idade ou se residem com o pai e/ou a mãe.

- Questões sobre vagas e matrículas em escolas particulares e públicas; avaliação das preferências do entrevistado sobre matricular seu(sua) filho(a) em creches e pré-escolas ou permitir que a criança permaneça fora da escola por mais tempo.

Estudos Feministas, Florianópolis, 25(1): 215-240, janeiro-abril/2017 219 
- Questionário sobre trabalho doméstico e cuidado com crianças (itens separados): número de horas, tipo de trabalho, contribuição própria e do cônjuge (quando existente).

- Perguntas sobre participação do(a) parceiro(a) na educação dos filhos e sobre pensão alimentícia no caso de pais separados ou divorciados.

- Características do trabalho do(a) entrevistado(a).

- Perguntas sobre divisão do poder com relação ao dinheiro e compras da casa.

- Renda individual e familiar.

- Dados de classificação econômica de acordo com a ABEP.

A coleta de dados foi focada em bairros com famílias que, na média, tivessem renda familiar inferior a $R \$ 1.500$.

${ }^{5}$ Os entrevistadores seguiram a recomendação de entrevistá-los separadamente para que as respostas não fossem viesadas ou que pais e mães não se sentissem constrangidos em responder perguntas, especialmente às ligadas ao comportamento do companheiro(a).

${ }^{6} \mathrm{Em}$ nossa amostra não é possíve analisar o caso de famílias monoparentais com somente pai residente por não termos encontrado respondentes com esse perfil.

${ }^{7}$ Ao longo do artigo, utilizaremos a expressão "mães não casadas" para incluir as mulheres solteiras, viúvas, separadas, divorciadas e desquitadas. As "mães casadas" são aquelas casadas formalmente ou que residem com um companheiro. Nesse sentido, por termos unificado, no questionário, os casais casados formalmente e os coabitantes sem registro formal, 0 texto utilizará um mesmo nome para ambas as situações. Do ponto de vista de análise, não consideramos, no momento da pesquisa, a necessidade de dividir essas categorias, pois o nosso interesse principal era a análise da situação das famílias com crianças em idade pré-escolar e suas necessidades de serviços públicos (vagas em creches, por exemplo) ou políticas públicas (com relação à proteção contra discriminação de gênero no trabalho, para citar uma delas).
Foram selecionados, para a amostra, os seguintes bairros: Brasilândia, Campo Grande, Capão Redondo, Casa Verde, Cidade Ademar, Cidade Dutra, Cidade Tiradentes, Ermelino Matarazo, Grajaú, Guaianazes, Iguatemi, Itaim Paulista, Jaraguá, Jardim Ângela, Jardim Helena, Jardim São Luis, José Bonifácio, Lajeado, Parelheiros, Parque São Domingos, República, São Domingos, São Mateus, Sacomã, Sapopemba, Tiradentes, Tremembé, Vila Matilde, Vila Jacui, Vila Andrade. Ao chegar ao bairro, o entrevistador se dirigia a um primeiro endereço sorteado e iniciava a pesquisa perguntando se, no domicílio, residia ao menos uma criança com menos de 6 anos de idade. Em caso negativo, a entrevista era concluída e ele se dirigia ao domicílio vizinho. Em caso positivo, ele prosseguia com a entrevista desde que o pai e/ou a mãe da criança residissem no mesmo domicílio.

No caso das famílias onde o casal residia no domicílio, entrevistamos separadamente ambos os pais; ${ }^{5}$ no caso das famílias monoparentais, a entrevista foi sempre realizada com a mãe residente. ${ }^{6}$ Os entrevistadores retornaram aos domicílios entrevistados tantas vezes quantas foram necessárias para garantir a entrevista de ambos os pais. No total, a pesquisa quantitativa incluiu 399 famílias: 300 de mães casadas e seus cônjuges - i.e., 300 pais, que residiam com a mãe de, pelo menos, um de seus filhos - e 99 mães não casadas. ${ }^{7}$ Assim, as famílias chefiadas por mulheres sem parceiro representam $25 \%$ da amostra, face à média nacional de $27 \%$ das famílias com crianças (PNAD 2013).

\section{Características sociodemográficas $e$ do mercado de trabalho da amostra}

A tabela 1 apresenta as estatísticas descritivas da amostra coletada na pesquisa. As mães não casadas são 
${ }^{8} \mathrm{~A}$ média de filhos dos homens (pais) é maior do que a média de filhos das mães casadas, pois existem homens (pais) entrevistados que têm filhos de relações anteriores à atual. ligeiramente mais jovens (27 anos, em média) do que as mulheres casadas (média de 29 anos de idade), e as mulheres são, em média, mais jovens do que os homens (média de 32 anos de idade). As mães não casadas têm, em média, 1,8 filhos, enquanto as mães e pais casados têm 2.1 e 2.2 filhos, ${ }^{8}$ respectivamente, próximos à taxa de fecundidade nacional de 1,8 filhos por mulher adulta. Com relação a aspectos de autoidentificação racial, mais de metade da amostra coletada se identifica como pertencente às raças "preta" ou "parda", enquando a segunda maior proporção de autoidenficação se dá com a raça "branca" (39\% para mulheres não casadas, $46 \%$ para mulheres casadas e $35 \%$ para os homens ).

Tabela 1: Estatísticas descritivas da amostra

\begin{tabular}{|c|c|c|c|}
\hline & 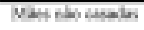 & 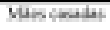 & 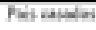 \\
\hline Kande & $5 \mathrm{~mm}$ & $29 \mathrm{mon}$ & $32 \mathrm{~cm}$ \\
\hline Ninwow de flax: & 13 & 2.1 & 22 \\
\hline \multicolumn{4}{|l|}{ sen } \\
\hline Brusca & 39,45 & 46,3 & $34 \%$ \\
\hline Prosace Pexta & 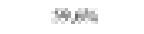 & $\$ 3.1 \%$ & ans \\
\hline Ceran & Ln & $1, n$ & 40 \\
\hline \multicolumn{4}{|l|}{ Etwatis } \\
\hline 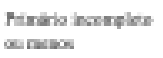 & 30,3 & 20,15 & se, $\pi$ \\
\hline 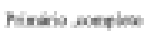 & 3036 & nw & STM \\
\hline 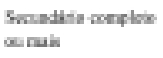 & $3 T, 4 \mathrm{~S}$ & 48,75 & $4, \pi$ \\
\hline \multirow{2}{*}{ 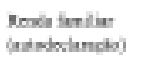 } & nsi.16ries & $n 31922,95$ & Nsicosue \\
\hline & $(1 \times 32,49)$ & (52213) & $(280,77)$ \\
\hline $\begin{array}{l}\text { Wrowas di } \\
\text { cheavipiea }\end{array}$ & $m$ & 256 & 291 \\
\hline
\end{tabular}

Fonte: Pesquisa "Conciliando Trabalho e Família" (2012) Nota: Os valores entre parênteses indicam o desvio padrão.

As mães casadas da amostra apresentam níveis mais elevados de educação, com quase metade delas tendo concluído o Ensino Médio em comparação com $45 \%$ dos pais e $37 \%$ das mães não casadas. No entanto, é importante salientar que $20 \%$ das mães não casadas e não empregadas relatam ainda estudar. Por fim, a renda mensal familiar das mulheres não casadas é, em média, $\mathrm{R} \$ 1.168$, representando $77 \%$ do valor da renda familiar média para as mulheres casadas, que é $R \$ 1$ 1.526. Um fato interessante a ressaltar é que os pais casados reportam uma renda familiar média de R\$1.688, valor superior ao declarado por suas esposas, mas, como ambos os dados são percepções individuais, é natural certa discrepância. 
${ }^{9}$ Também questionamos as mães se elas estavam ativas no mercado de trabalho quando o filho mais novo nasceu e se receberam licença maternidade: $58 \%$ das mães casadas e $40 \%$ das mães não casadas receberam licença maternidade, o que significa que o benefício é inferior à sua eligibilidade.

${ }^{10} \mathrm{~A}$ respeito, ver: Contreras et al. (2010) para uma visão geral da literatura econômica e EspingAndersen (2009) para uma visão geral da literatura científica em sociologia e política.

1 ECEC é a sigla utilizada pela OCDE (Organização para Cooperação e Desenvolvimento Econômico) para designar Early Childhood Education and Care, livremente traduzida por Educação e Cuidado para Primeira Infância. Utilizar-se-á, ao longo do texto, a sigla original ECEC.

\footnotetext{
12 Uma emenda constitucional aprovada em 2009 torna, a partir de 2016, a frequência escolar obrigatória para crianças com 4 e 5 anos anos de idade.
}

Os dados da pesquisa demonstram, sem surpresa, que os pais casados têm a maior taxa de emprego (de $90 \%$ ), enquanto somente $60 \%$ das mães não casadas e $47,3 \%$ das mães casadas encontram-se empregadas. Também é interessante o fato de que os pais são os mais propensos a serem registrados pelo INSS, isto é, no mercado de trabalho formal; de todos os pais que estavam empregados, $70 \%$ eram registrados pelo INSS, enquanto que a cifra era de 53\% para as mães não casadas e $63 \%$ para as mães casadas. Cerca de metade das mães não casadas que trabalham e pouco menos de um terço de todas as mães que trabalham não têm direito à licença-maternidade. ${ }^{9}$

\subsection{Acesso a creches e pré-escolas}

Estudos empíricos têm demonstrado que países ou regiões que disponibilizam acesso a creches a preços acessíveis têm taxas de participação da força de trabalho muito maior entre mães. ${ }^{10}$ A própria dupla jornada das mulheres, que será discutida mais profundamente nas seções a seguir, pode ser amenizada com uma maior rede de serviços públicos que complementem o cuidado individual com crianças (Cristiane SOARES e Ana Lucia SABOIA, 2007). A literatura sobre a América Latina mostra resultados semelhantes. Tanto para o Chile como para a Argentina, estudos concluíram que o acesso à educação pré-escolar e a creches de baixo custo (ECEC ${ }^{11}$ ) ou escolas em tempo integral tem efeito positivo sobre as taxas de participação na força de trabalho das mães (Samuel BERLINSKI; Sebastian GALLIANI e Patrick McEWAN, 2008; Dante CONTRERAS; Paulina SEPULVEDA; Soledad CABRERA, 2009; Patricia MEDRANO, 2009). Outros estudos mostram que o acesso a ECECs formais permite às mães alterarem a natureza de sua participação no mercado de trabalho de tempo parcial para integral (BERLINSKI; GALLIANI e McEWAN, 2008, na Argentina; Kelly HALLMAN; Agnes R. QUISUMBING; Marie RUEL; Benedicte de LA BRIÈRE, 2005; Agnes R. QUISUMBING, 2003 sobre Guatemala; Mirela CARVALHO et al., citado por Laura CHIODA, 2010, para Brasil) e mudar de informal para formal o seu contrato de trabalho (CHIODA, 2011).

É um direito constitucional, no Brasil, a disponibilidade de ECECs gratuita a partir de quatro meses de idade da criança, o que coloca o país entre os mais progressistas do mundo com relação a esse direito. Para a faixa etária de 4 e 5 anos de idade, as taxas de cobertura são cerca de $80 \%$, refletindo o objetivo do Brasil de cobertura universal para esta faixa etária a partir de 2016. ${ }^{12}$ Mesmo assim, no que tange à necessidade de cuidado com essas crianças, o dia médio de escola tem duração de 4 horas, significativamente inferior 
à necessidade de um dia integral de trabalho (tipicamente, de 8 horas diárias).

Dentre as mães que trabalham fora, metade tem seus filhos com idade entre 0-3 anos em creches, enquanto que menos de um terço das mães que não trabalham os têm. A grande maioria das crianças está em escolas públicas.

Claramente, os números não apresentam as razões que estão por detrás desta baixa cobertura de inclusão escolar. Entretanto, a razão preponderante para explicar o motivo pelo qual as crianças não estavam matriculadas em creches públicas é a não existência de vagas. Dos entrevistados que não têm filhos em ECECs públicos (51\% das famílias), ao menos metade tem suas crianças em lista de espera, o que confirma uma grande demanda não atendida por este serviço. O maior percentual de mães com filhos na lista de espera por ECECs (65\%) está entre mães não casadas que trabalham. Quando se perguntou aos pais sobre qual o motivo pelo qual seus filhos não estavam matriculados em ECECs privados, sem surpresa, o principal fator foi o custo. Apenas $7 \%$ das famílias da amostra tinham um filho matriculado em ECEC privado, e, mesmo para essas famílias, a razão predominante para esta escolha em todos os tipos de família foi a falta de vagas em ECECs públicos.

Para os pais cujos filhos estavam matriculados em creche pública, perguntou-se sobre a preferência por horário mais amplo de atendimento.

A figura 1 indica que entre 45 a $60 \%$ de pais que trabalham fora ou que não trabalham gostariam de escolas abertas e disponíveis por um período mais amplo de atendimento. Para as mães que não trabalham, a possibilidade de procurar um emprego é a razão mais importante, enquanto que, para os pais e mães casados e que trabalham fora, o principal motivo é não ter de pagar ou depender de outras formas de cuidado com a criança, pois dependem, muitas vezes, de um cuidado informal (por exemplo, uma pessoa que leve e/ou busque a criança na escola). Os cuidados informais envolvem familiares e vizinhos e podem ou não ser remunerados. Para um quinto dos pais, a principal razão para querer mais horas de creche é para que sua esposa possa trabalhar.

\subsection{A divisão sexual do trabalho entre mães e pais}

Pesquisas para diversos países mostram que, dentro da família, as mães ainda são as maiores responsáveis por cuidar das crianças, embora o envolvimento dos pais tenha apresentado um aumento sensível, especialmente quando suas esposas trabalham fora de casa (Gøsta ESPING- 
Figura 1: Razões para desejar que a escola funcione por mais horas durante a semana, por tipo de família

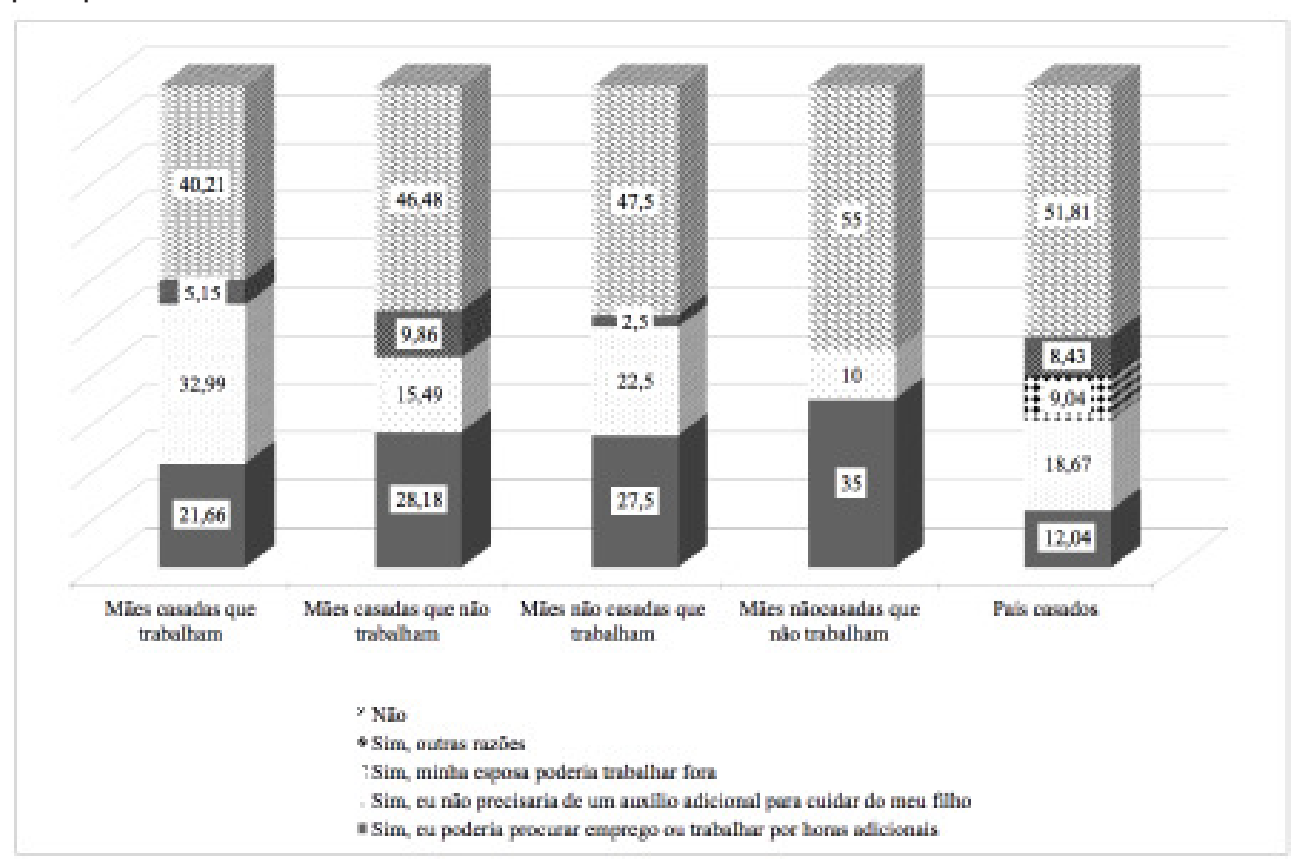

Fonte: Pesquisa "Conciliando Trabalho e Família" (2012)

ANDERSEN, 2009). No entanto, esta tendência varia muito, dependendo do país (mais uma vez, os países nórdicos têm os pais mais envolvidos) e por nível sócio-econômico. Nos países industrializados, os pais de famílias de baixa renda e escolaridade são os que se dedicam menos ao cuidado com as crianças. Esping-Andersen (2009) também mostra que a diferença entre a participação de mães e pais é menor para o trabalho desejável de cuidar das crianças do que para o trabalho tedioso de manutenção do lar. Outros sociólogos afirmam que, apesar do aumento da atenção para o papel do pai, "a função central da paternidade continua a ser a prestação de apoio econômico" (William MARSIGLIO; Paul R. AMATO; Randal D. DAY; Michael E. LAMB, 2000; Shawn CHRISTIANSEN; Rob PALKOVITZ, 2001) e os papéis tradicionais de gênero permanecem fortes (STÄHLI; LE GOFF; WIDMER, 2009). A literatura sobre o Brasil encontra uma dinâmica semelhante. Em um destes estudos, mulheres casadas que trabalham em tempo integral (entre 40 e 44 horas semanais) dedicam, em média, 20 horas semanais para trabalhos domésticos, enquanto os homens que trabalhavam o mesmo número de horas no mercado de 
${ }^{13}$ É interessante perceber que as diferentes perspectivas sobre 0 trabalho e a responsabilidade entre cônjuges leva em consideração diferentes perspectivas também nas relações de poder dentro da família (ou quem é o responsável pelo cuidado e quem "ajuda" o responsável). Nesse sentido, Hirata (2016) contribui para o entendimento dessas relações inclusive com a perspectiva de classe e raça - na questão da "interseccionalidade" na interdependência das relações.

${ }^{14}$ As categorias expostas acima forarm as categorias consideradas "trabalho doméstico" tanto pelos participantes dos grupos focais como no pré-teste, onde as questões eram colocadas de forma aberta. Para facilitar o entendimento do entrevistado, o entrevistador tanto perguntava o número de horas dedicados ao trabalho doméstico como, também, usando um cartão, pedia para o(a) entrevistado(a) apontar a ordem da tarefa em que o(a) mesmo(a) mais gastava seu tempo até aquela que ele(a) gastava menos tempo. Para o caso de tarefas de cuidado com as crianças, usamos o mesmo procedimento. trabalho contribuíam com apenas 5 horas semanais para o mesmo fim (Regina MADALOZZO; Sérgio Ricardo MARTINS; Ludmila SHIRATORI, 2010).

Os dados da pesquisa permitem comparar as estimativas dessa divisão de trabalho do ponto de vista do entrevistado, e, também, sob a perspectiva de seu cônjuge..$^{13}$ Diferente da forma como a questão do trabalho doméstico e o cuidado com as crianças é abordada pelo Instituto Brasileiro de Geografia e Estatística (IBGE) na PNAD - com a união do tempo gasto em afazeres domésticos e cuidados com as crianças -, a presente pesquisa diferenciou o tempo gasto com as tarefas domésticas (limpar a casa, ${ }^{14}$ cuidar da cozinha, cuidar das roupas, cuidar do automóvel ou moto, cuidar das plantas ou animais domésticos, consertar objetos da casa) das atividades de cuidado com crianças (dar banho, trocar fraldas/roupas, fazer dormir, dar comida, brincar, levar e/ou buscar na escola, levar ao médico/ dentista/etc.).

Maria Cristina Aranha BRUSCHINI e Arlene Martínez RICOLDI (2009) apresentam uma análise bastante profunda da situação do trabalho doméstico e do cuidado com crianças utilizando tanto os dados da PNAD 2002 como, também, dados coletados com grupos focais. Embora ambas as tarefas sejam de "cuidado", como ressaltado em Bruschini e Ricoldi (2009), a tarefa de cuidar dos filhos/ crianças é considerada, usualmente, de maior prestígio ou valor, até mesmo pela cultura de valorização da educação e do cuidado. Por envolver afeto, segundo a amostragem dessas pesquisadoras, as tarefas de cuidado não deveriam ser consideradas "tarefas domésticas". Seguindo essa linha de raciocínio, dividimos o tempo gasto com essas tarefas em nosso questionário e, assim, apresentamos os dados separadamente.

As figuras 2 e 3 apresentam a quantidade de tempo dedicado ao cuidado de crianças e ao trabalho doméstico por sexo, situação de emprego e tipo de família. Ambas as figuras apresentam as estimativas próprias (das esposas e maridos) e de seus cônjuges para tempo dedicado ao cuidado das crianças e tempo dedicado ao trabalho doméstico. Para as mães não casadas, a declaração é somente das estimativas próprias.

Diversos fatores se destacam. Em primeiro lugar, como a figura 2 indica, a diferença entre os autorrelatos e as percepções do cônjuge é praticamente inexistente para casais onde pais e mães participam do mercado de trabalho. Para os casais em que a mãe não está ocupada, existe uma diferença mais proeminente com relação ao papel do pai: as mães percebem a participação dos pais em aproximadamente 4 horas semanais a menos no 
cuidado com os filhos do que os pais afirmam fazer. $O$ contrário - percepção dos pais com relação às horas que as mães dedicam aos filhos - apresenta uma diferença de apenas uma hora semanal.

Figura 2: Horas por semana dedicadas ao cuidado com as crianças, por tipo de família

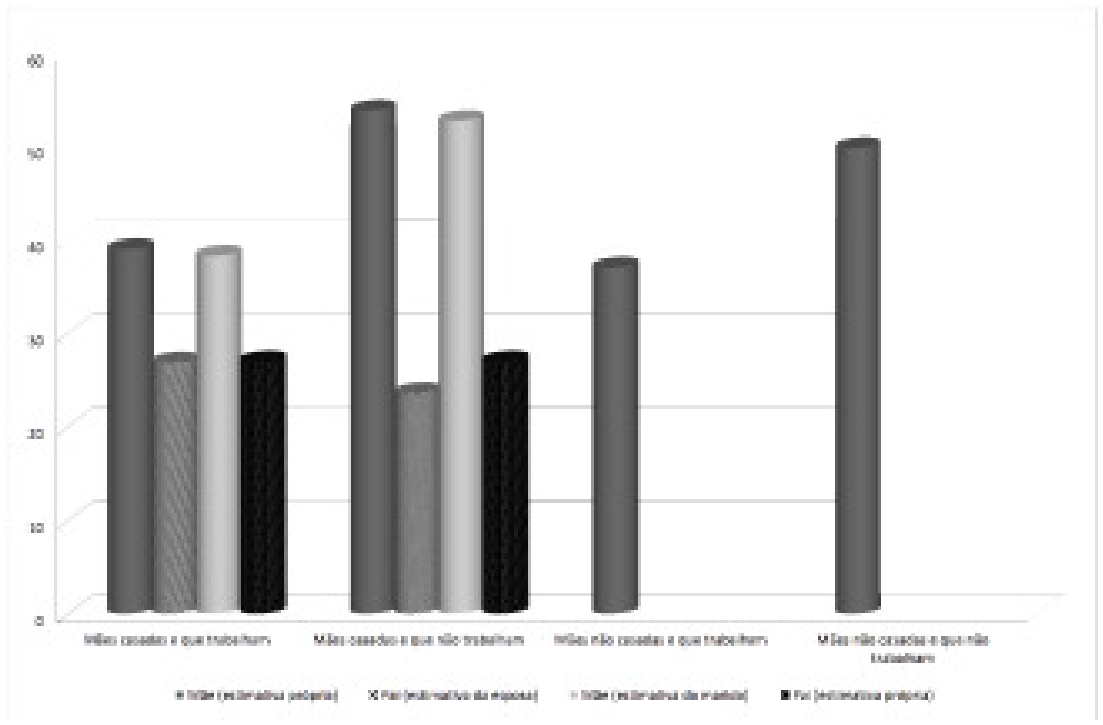

Fonte: Pesquisa "Conciliando Trabalho e Família" (2012)

Focando a partir de agora na percepção própria quanto à dedicação aos filhos, percebe-se que as mães que trabalham fora gastam menos tempo no cuidado para com seus filhos do que as mães que não trabalham. Essa diferença é, em média, 10 horas semanais a menos (o que não é, contudo, próximo à carga de trabalho semanal por período integral). Mães casadas que não participam do mercado de trabalho gastam mais tempo cuidando de seus filhos, 53,7 horas por semana, enquanto que mães não casadas que não trabalham gastam 49,7 horas semanais no cuidado com as crianças, representando uma diferença de 4 horas por semana. Mães casadas e que trabalham fora de casa gastam 38,9 horas por semana no cuidado com as crianças, enquanto as mães não casadas que trabalham gastam 36,9 horas por semana cuidando de seus filhos. Em geral, mães não casadas, seja trabalhando ou não, gastam um pouco menos de tempo cuidando de seus filhos do que as mães casadas. Aqui é importante ressaltar que pode existir uma variável não existente e com potencial 
${ }^{15}$ Parte das horas reportadas no cuidado com as crianças, possivelmente, é feita conjuntamente, i.e., quando ambos os pais estão em contato com seus filhos. explicação para essa diferença: o número de horas dispendido nos estudos. Não medimos o número de horas por semana dedicadas ao estudo em geral, mas nossos dados mostram que $20 \%$ das mães não casadas que não estão trabalhando se encontram estudando, enquanto 10\% das mães casadas que não trabalham o fazem.

Um terceiro fator interessante que a figura 2 aponta é que a participação dos pais casados no cuidado com as crianças está longe de ser insignificante: em média eles dedicam 27 horas por semana para esse fim, independentemente de suas esposas trabalharem fora de casa. Embora um fator interessante: ele também indica que os pais não parecem adaptar seu comportamento e aumentar a sua parcela de responsabilidade no cuidado das crianças quando suas mulheres trabalham, o que implica que o tempo gasto com as crianças é mais uma preferência por parte dos pais do que uma questão de responsabilidade parental - é a opção por passar o tempo com seus filhos, mas não, necessariamente, assumir a responsabilidade adicional no caso de suas esposas dedicarem tempo ao mercado de trabalho. Os grupos focais dão apoio a essa interpretação, pois tanto pais como mães percebiam elas - mães - como principais responsáveis pelo cuidado com as crianças, enquanto os pais têm a possibilidade de escolher "ajudar" as suas mulheres com esta responsabilidade quando se sentem inclinados a isso. ${ }^{15} \mathrm{Em}$ suma, para casais onde as mães trabalham fora, elas gastam $50 \%$ mais de horas no cuidado com seus filhos do que os pais e, para aqueles casais onde as mulheres não trabalham fora, as mães dedicam o dobro de horas do que os pais no cuidado com as crianças. Por fim, filhos de mães não casadas simplesmente recebem menos tempo de atenção parental total.

A figura 3 aponta o tempo semanal gasto em tarefas domésticas, que podem ou não se sobrepor ao tempo de cuidado com as crianças. Aqui, em primeiro lugar, é possível observar a existência de uma lacuna clara nas percepções dos casais. Os homens têm uma percepção de mais tempo gasto em tarefas domésticas tanto desempenhadas por eles como por elas. Mulheres casadas que trabalham fora têm a percepção de que trabalham 2 horas a menos por semana do que os maridos percebem e que eles trabalham 1,5 hora a menos do que declaram. Mulheres casadas que não trabalham fora têm uma visão ainda mais dissonante do que a de seus maridos: elas declaram gastar 10 horas a menos em trabalho doméstico por semana do que eles percebem e que eles dedicam 3 horas a menos do que declaram.

Em segundo lugar, as autodeclarações, entre as mães casadas, tanto aquelas que trabalham fora de casa como as que não trabalham fora, é a de que gastam praticamente 
Figura 3: Horas por semana dedicadas ao trabalho doméstico, por tipo de família

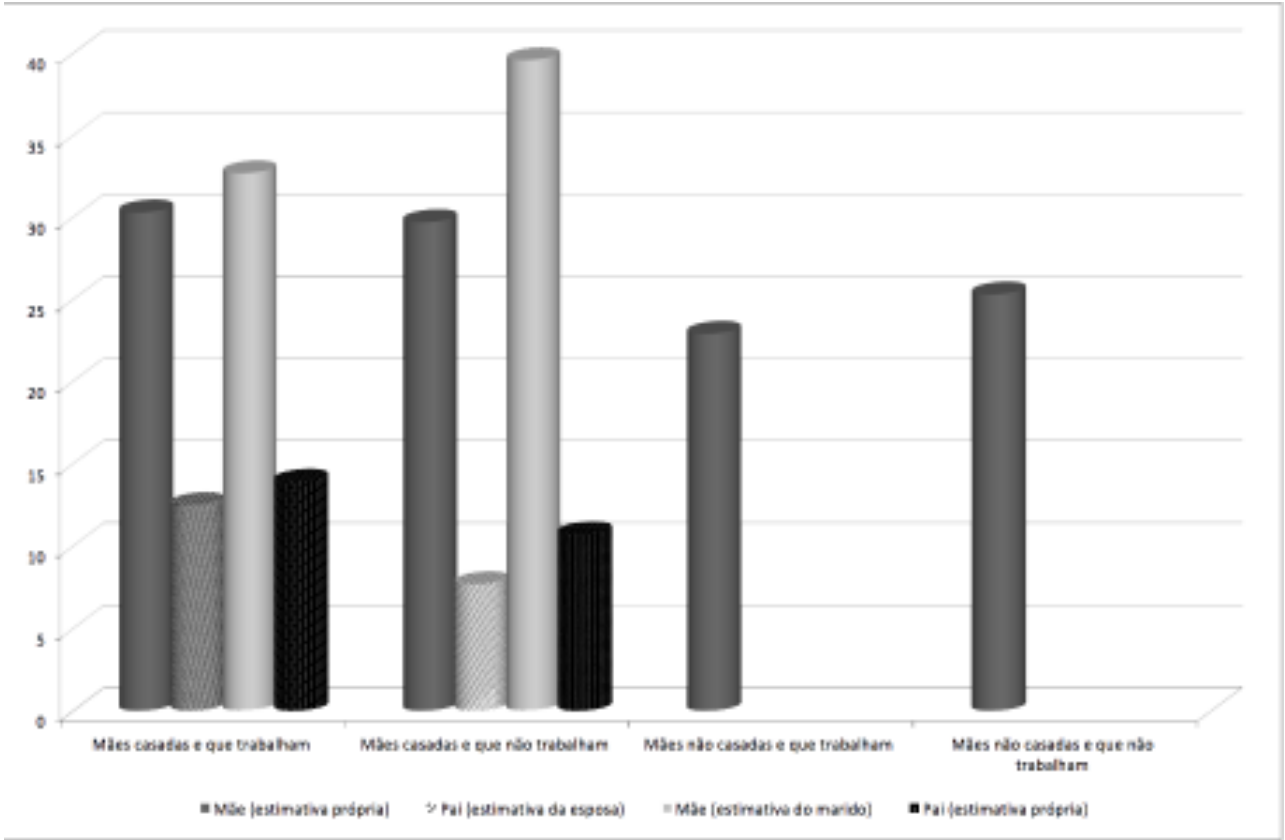

Fonte: Pesquisa "Conciliando Trabalho e Família" (2012)

a mesma quantidade de tempo por semana em tarefas domésticas: cerca de 30 horas semanais. As mães não casadas, por outro lado, dedicam consideravelmente menos tempo a essas tarefas: 25,3 horas se não trabalham fora de casa e 22,9 horas se elas trabalham fora de casa. Isso dá suporte a um estudo anterior, baseado em dados do Brasil, que constatou que essas mães com filhos menores de 14 anos de idade gastam 2 horas adicionais por semana em tarefas domésticas se um homem estiver residindo com a família do que se um homem não estiver presente (Gary BARKER, Juan Manuel CONTRERAS, Brian HEILMAN, Ajay SINGH; Ravi VERMA, 2011, p. 36).

Em terceiro lugar, os pais com as mulheres que não trabalham reportam gastar 10,7 horas por semana em tarefas domésticas, enquanto os pais com as esposas que trabalham fora gastam, em média, 13,9 horas semanais. Por outro lado, a diferença de gênero entre mães e pais no trabalho doméstico é mais ampla: quando a mãe não trabalha, ela gasta 2,8 vezes mais horas no trabalho doméstico do que o marido; mesmo quando trabalha, ela ainda gasta 2,2 vezes mais horas no trabalho doméstico do que seu marido. 
A figura 4 mostra a quantidade semanal total de tempo gasto, via autodeclaração, no trabalho remunerado (para pais e mães que trabalham), transporte (também para os que trabalham fora de casa), cuidado com as crianças e trabalho doméstico.

Figura 4: Horas por semana dedicadas ao trabalho doméstico, cuidado com crianças, trabalho remunerado e transporte, por gênero e tipo de família

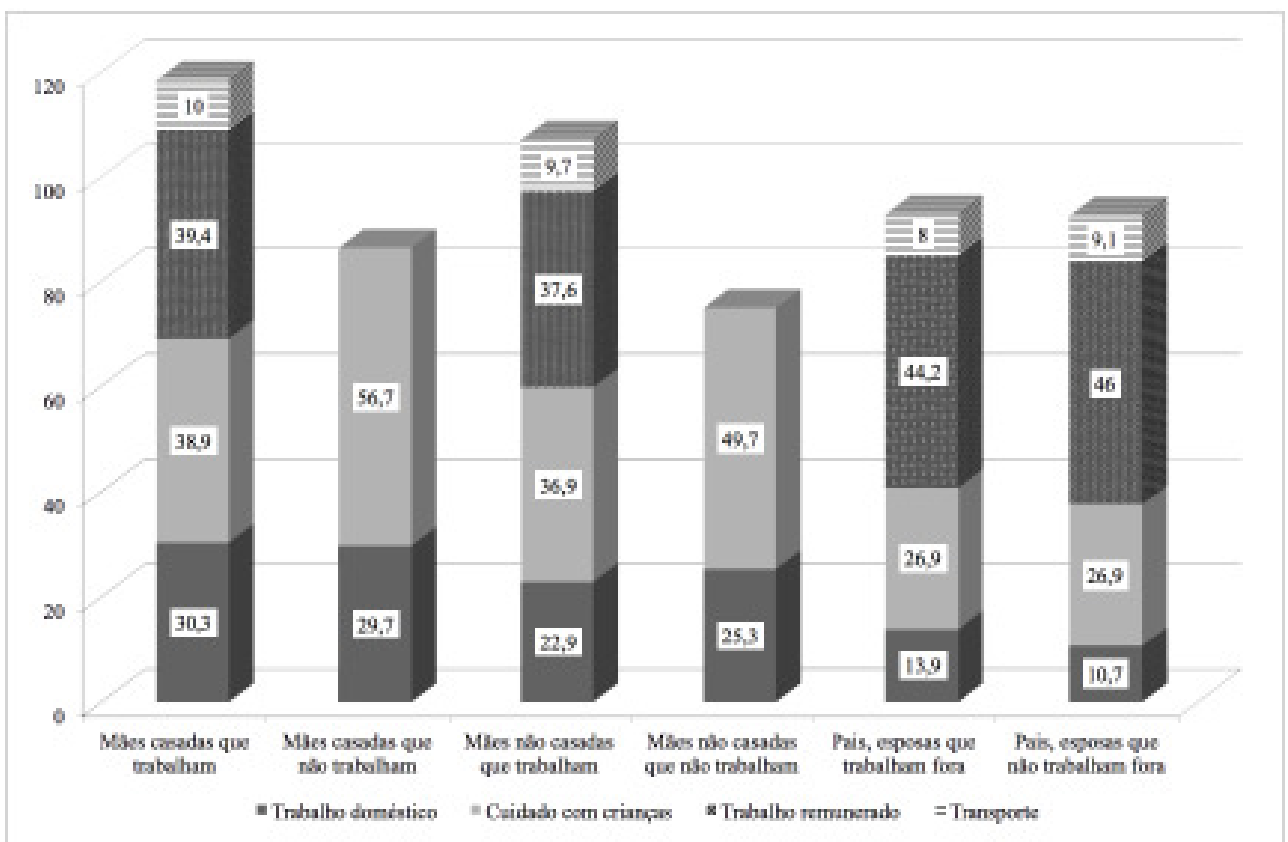

Fonte: Pesquisa "Conciliando Trabalho e Família" (2012)

Quando todas as horas são computadas em conjunto, incluindo o transporte, a maior carga de trabalho se revela entre as mães casadas que também trabalham fora de casa. Em segundo lugar, para mães não casadas que trabalham. Isso confirma que a "dupla carga" para as mães que trabalham existe. Para os pais, o tempo total de trabalho é praticamente o mesmo se suas esposas trabalham fora de casa ou não, mais uma vez apoiando a hipótese de que os pais não alteram seu comportamento em resposta a suas esposas que trabalharem fora de casa. Bruschini (2006) criticava o status quo onde o trabalho doméstico é considerado inatividade econômica. Em seu artigo, a autora apontava a dissonância entre as médias semanais de

${ }^{16}$ Lembrando que a PNAD inclui, no trabalho doméstico, as horas dedicadas ao cuidado com as crianças. trabalho doméstico entre homens e mulheres usando dados da PNAD 2002:16 27,2 horas para as mulheres e 10,6 para os 
homens. Comparando com o presente estudo, as médias, somente dessas duas tarefas nos dados reportados na figura 4, são bastante superiores. Entretanto, como a pergunta feita pelo IBGE agrega os dois tipos de trabalho (doméstico e de cuidado), é bastante plausível que as pessoas, ao reportar o número de horas dedicadas aos mesmos, esqueçam-se de períodos de sobreposição. Por exemplo, quando perguntadas pelas horas de trabalho doméstico, as pessoas podem pensar no número de horas que estiveram cozinhando, limpando a casa etc. e reportam esse número. Ao serem perguntadas sobre o número de horas que dedicaram ao cuidado com as crianças, elas reportam o mesmo e, em diversos períodos, elas estavam fazendo as duas coisas concomitantemente. Ao empregar a técnica utilizada pelo IBGE, a contagem dupla se desfaz. Ao nosso entender, por serem trabalhos distintos -e até mesmo com diferentes status, como apontam Bruschini e Ricoldi (2012) - é mais adequado medi-los separadamente, mesmo quando sobrepostos.

Outro ponto interessante da pesquisa é a forma como os casais tomam decisões financeiras. Perguntou-se aos entrevistados quem era responsável pela administração do dinheiro em suas famílias. Para mulheres que trabalhavam fora de casa, $17,8 \%$ responderam que era o marido/ companheiro ou outra pessoa que não ela, enquanto para aquelas que não trabalhavam fora, esse percentual chegou a $41,6 \%$. Esses números indicam que o poder decisório na questão financeira e, possivelmente, o poder de barganha envolvido em outras negociações que são baseadas em decisões financeiras é muito superior para mulheres que "ganham seu próprio dinheiro" do que para aquelas que dependem financeiramente de outras pessoas.

\subsection{As mães não casadas e os "pais ausentes"}

No caso de mães não casadas, os pais das crianças no Brasil são obrigados, por lei, a pagar uma parte de sua renda em apoio à criança (e muitos podem desejar fazê-lo, independentemente da lei). A falta de pagamento, quando reportada à Justiça, pode resultar em prisão. Ao todo, 37,5\% das famílias em nossa pesquisa têm crianças na residência cujos pais não vivem com eles $(25 \%$ são filhos de mães não casadas e outros $12,5 \%$ são crianças de famílias com presença de um casal residente, mas cujo pai não é o homem residente com a família).

Das mulheres entrevistadas, apenas cerca de um quarto $(27 \%)$ dos pais não residentes têm um acordo legal e, destes, $80 \%$ contribui ao menos ocasionalmente com o sustento de seus filhos. Por outro lado, $57 \%$ dos pais que não 
17 Considerando restrições de financiamento e o tempo gasto com os questionários, somente foram questionadas as mães nesse quesito. têm um acordo legal nunca paga pensão alimentícia. No total, metade de todos os pais não residentes nunca fornece apoio financeiro para seus filhos, enquanto pouco mais de um terço (35\%) os apoia com regularidade. O restante (15\%) contribui de forma eventual. Esses dados indicam que, entre mães e pais que não vivem juntos, existe uma lacuna de gênero substancial com relação ao apoio financeiro para seus filhos.

Também se questionou as mães se os pais não residentes passam algum tempo - ao menos uma vez por semana - com seus filhos. Aqui, os resultados são gritantes: menos de $5 \%$ dos pais não residentes veem seus filhos pelo menos uma vez por semana. Isto evidencia uma lacuna de gênero dramática no tempo dedicado ao cuidado das crianças entre casais não coabitantes.

Estes resultados, em conjunto, indicam que, para muitos pais, a renda e o tempo que dedicam à sua prole é mínimo quando não coabitam na mesma residência. Como resultado, as mães não casadas têm o desafio de liderar uma família com renda menor, maior necessidade de trabalho no mercado e, também, são dependentes de outras instâncias de arranjos com os cuidados para com seus filhos tanto formal como informalmente.

\subsection{Redes de cuidados informais}

Dada a situação financeira dessas famílias, combinada com a evidente falta de vagas em creches e pré-escolas, se faz importante o exame da disponibilidade de redes informais de cuidado. Ou seja, pessoas que possam auxiliar mães e pais no cuidado diário com as crianças. ${ }^{17}$ Perguntouse qual o tipo de ajuda informal que a família recebia semanalmente para cuidar das crianças pequenas, inclusive se essa ajuda era proveniente dos filhos mais velhos, avós maternas e paternas, avôs maternos e paternos, outros parentes, amigos, vizinhos ou trabalhadores domésticos (babás, em especial). Em seguida, agruparam-se as instâncias de ajuda recebidas em "ajuda vinda de um homem" e "ajuda vinda de uma mulher".

As respostas à pesquisa apontam claramente a proeminência de ajuda informal por parte de outras mulheres. Entre as famílias com ambos os pais presentes ou somente com as mães residentes, independente dessas mães trabalharem ou não fora de casa, $70 \%$ das famílias recebem ajuda de outras mulheres. A grande maioria é não remunerada. Entre as mães não casadas que trabalham, cada uma delas recebe algum tipo de ajuda informal por parte de outra mulher; na verdade, é provável que, sem essa ajuda, as mães não fossem capazes de se envolver no 
mercado de trabalho e entrariam na categoria de mães não casadas que não trabalham fora. Pouco menos de $70 \%$ das mães não casadas que não trabalham - muitas das quais ainda estudam - recebem ajuda informal por parte de outras mulheres.

Já a ajuda informal por parte de homens é bem menos comum, variando de $23 \%$ entre mães casadas que não trabalham fora até $38 \%$ para as mães não casadas que trabalham fora. Para as mulheres não casadas que não trabalham fora, toda a ajuda informal recebida é não remunerada, provavelmente relacionada ao fato de que a baixa renda familiar impede a contratação desse serviço. Entre mães não casadas que trabalham fora, um quarto da ajuda informal vinda por parte de homens é remunerada, enquanto se observa que, para as mães casadas, a ajuda remunerada é insignificante.

\subsection{Preferências vs restrições em conciliar vida profissional e familiar}

Com a finalidade de testar as teorias que tratam das preferências pessoais ou com relação ao conflito de papéis, duas questões se colocam: em primeiro lugar, pedimos às mães e pais que não trabalham o motivo pelo qual eles não estavam empregados. Em segundo lugar, examinou-se a autoavaliação das mudanças de relações com o mercado de trabalho após o nascimento do(s) filhos(s).

Agregou-se as respostas para a primeira pergunta em 3 diferentes categorias: aqueles que não trabalham por escolha própria, isto é, por preferências pessoais ou familiares; aqueles que estão procurando, mas não conseguem encontrar trabalho; e, por fim, aqueles que não trabalham por não ter acesso a creches. Os dois últimos foram considerados como "restrições", enquanto que, na categoria de preferência, foram agregadas as seguintes razões: preferência pessoal por ficar em casa com as crianças; um dos cônjuges prefere que a mãe (ou pai) fique em casa com as crianças; frequência à escola que impede o trabalho concomitante; salários disponíveis abaixo do nível desejado; problemas de saúde ou incapacidade física; licença-maternidade e aposentadoria. Enquanto alguns desses motivos (por exemplo, salários abaixo do nível desejado, preferência do cônjuge e problemas de saúde) possam ser considerados como restrições, a opção foi por mensurar quando os pais e mães estão ativamente empenhados em participar da força de trabalho ou não e, dessa forma, interpretar as restrições de forma mais focada.

Segundo os dados coletados, no mínimo $20 \%$ das mães casadas e não casadas não trabalham fora de casa 
${ }^{18}$ Esse percenual inclui um pai
que se declara incapaz para 0 trabalho e dois pais aposentados.

${ }^{19}$ Embora seja necessário ressaltar que esse percentual inclui somente 2 (duas) observações. porque elas não têm quem cuide de seus filhos. Já os pais sempre analisando os pais casados - não têm esse problema. $35 \%$ das mães não casadas, $18 \%$ das mães casadas e $50 \%$ dos pais casados - e não empregados estão à procura de trabalho, mas não conseguem encontrálo. Finalmente, apenas $43 \%$ das mães não casadas - e não empregadas - não se encontram empregadas por escolha própria de permanecer fora do mercado de trabalho, enquanto o percentual é $50 \%$ superior para as mães casadas. Dos homens que não estavam trabalhando durante a pesquisa, $50 \%$ dos pais $^{18}$ se enquadram nesta categoria. Das mães casadas cujas respostas são agrupadas na categoria de preferência ou opção por não trabalhar, $56 \%$ preferem ficar em casa com seus filhos, enquanto que, para $15, \%$ delas, foi seu marido quem manifestou a preferência de que ela ficasse em casa com as crianças e $2 \%$ ainda estão estudando. Para as mães não casadas, entre as que se encaixam na categoria de preferência própria, $53 \%$ preferem ficar em casa com seus filhos, enquanto $24 \%$ estão estudando. Nenhuma mãe não casada optou por ficar em casa porque os salários são muito baixos, enquanto que $2 \%$ das mães casadas se encontram nesta categoria. ${ }^{19}$

Vários pontos são dignos de nota. Em primeiro lugar, a diferença de empregabilidade global entre mães casadas e não casadas é quase inteiramente composta devido à escolha das mães casadas em ficar de fora do mercado de trabalho, em grande parte impulsionada pela preferência de seus maridos. Presumivelmente, as mães não casadas, com suas rendas familiares significativamente inferiores às famílias com mães e pais residentes, não têm a mesma opção. Em segundo lugar, os níveis mais elevados de emprego entre as mães não casadas, comparados às mães casadas são devidos ao engajamento em trabalhos informais ao invés da participação do mercado formal de trabalho. Se considerarmos esta uma proxy para a qualidade do emprego, parece que as mães não casadas se sujeitam a aceitar empregos de menor qualidade do que as mães casadas. Finalmente e mais impressionante, mais de metade das mães não casadas que não trabalham (58\%) e quase metade das mães casadas que também não trabalham (38\%) estão desocupadas por duas restrições: elas estão procurando, mas não conseguem encontrar trabalho ou não têm acesso a cuidados com seus filhos e, por isso, não podem trabalhar.

Um segundo ponto interessante é o exame da autoavaliação com relação às mudanças do mercado de trabalho após o nascimento do(s) filho(s). Desde a condução dos grupos focais foi possível perceber que, mesmo que trabalhar fora de casa fosse algo valorizado por muitas mães 
${ }^{20}$ Para garantir a confiabilidade da codificação, as respostas foram codificadas individualmente por duas pesquisadoras e a correlação de $95 \%$ foi auferida. Em seguida, as respostas não similares foram reanalisadas e categorizadas via consenso. (quer trabalhassem ou não), as mães também percebiam o conflito entre família e trabalho de forma mais intensa; os grupos focais formados por mulheres gastavam grande parte do tempo das entrevistas na discussão a respeito do conforto de suas famílias, enquanto, entre os homens, as respostas mais enfáticas tinham como temática o trabalho. Os homens declaravam a percepção de que a responsabilidade com as crianças era das mães, eles somente "ajudavam". Um dos entrevitados declarou, inclusive, concordar que sua esposa trabalhasse fora de casa desde que ela também conseguisse manter o gerenciamento das responsabilidades com a casa e a família.

Na pesquisa, uma pergunta com resposta aberta foi incluída para avaliar se o nascimento dos filhos tinha afetado a relação do pai/mãe no mercado de trabalho e, em caso positivo, de qual forma. Independentemente de estarem ou não casadas ou empregadas, mais da metade das mães (55\%) responderam que sua relação com o mercado de trabalho mudou depois de terem filhos, enquanto somente $21 \%$ dos pais disseram ter percebido essa mudança, sendo que essa resposta se refere somente aos pais residentes no domicílio. ${ }^{20}$ Alguns indivíduos se referem às tentativas de equilibrar as demandas do trabalho com as da família e não é possível perceber se a indicação é de aumento ou redução de um dos lados. Essas respostas foram classificadas como alterações neutras. Segundo os dados coletados, $7 \%$ dos pais $(33 \%$ dos pais que perceberam mudança na relação com o trabalho após o nascimento dos filhos) e 6\% das mães (10\% das mães que perceberam alterações na relação trabalhista após o nascimento dos filhos) encontramse nessa categoria. As afirmações vão desde a percepção de que o trabalho exige um tempo de dedicação que poderia ser dado aos filhos, mas que é compensado pelo retorno financeiro, até declarações de que a escolha de local de trabalho foi afetada.

Uma segunda categoria é daqueles indivíduos que perceberam alterações negativas na relação trabalhista. Novamente, $7 \%$ dos homens $33 \%$ dos que perceberam mudanças no mercado de trabalho) encaixam-se nessa definição. Já, entre as mulheres, $48 \%$ delas (o que representa $88 \%$ das que perceberam alterações na relação de trabalho) estão nessa categoria. As afirmações dos homens estão mais frequentemente relacionadas ao fato de que se preocupam com o bem-estar dos filhos enquanto no trabalho. Já as mulheres também declaram essa preocupação como efeito negativo na relação trabalhista, mas, em maior número, fazem afirmações a respeito de tratamento discriminatório com relação aos empregadores que temem contratar ou manter empregadas com filhos pequenos. 
Por fim, uma parte dos entrevistados percebe alterações positivas no mercado de trabalho: $7 \%$ dos homens e $1 \%$ das mulheres afirmam que a relação trabalhista melhorou após o nascimento dos filhos. Os homens, de forma geral, afirmam que a paternidade os fez mais responsáveis e que os patrões perceberam e os recompensam por isso. Já as 4 mulheres que apontam melhoras no mercado de trabalho falam sobre a motivação extra que os filhos dão para que elas permaneçam no mercado e tenham melhora financeira para a família.

\section{Conclusões}

A presente pesquisa é fruto de um trabalho de campo realizado em 2012 em bairros predominantemente de baixa renda em São Paulo. Com base teórica na teoria de preferências e dos conflitos, a pesquisa foi fundamentalmente focada em famílias com presença de crianças menores de 6 anos de idade e em questões que evidenciassem as escolhas com relação ao trabalho remunerado e não remunerado, bem como a divisão entre os gêneros das responsabilidades financeiras e familiares.

Os resultados dessa pesquisa indicam que as mulheres, conforme esperado, ainda suportam um peso desproporcinoal na responsabilidade pelo cuidado das crianças e, no caso das mães não casadas, também com relação ao sustento da família. As obrigações de cuidado são distribuídas de forma desigual entre os pais, mesmo quando as mães trabalham fora de casa e essas obrigações acabam por restringir a possibilidade de trabalho delas, mesmo quando o desejam. A falta de de creches e pré-escolas com custo baixo ou pagas pelo governo tem um impacto direto na decisão das mães em participar (ou não) do mercado de trabalho. Nesse sentido, o presente estudo complementa o estudo de Sorj, Adriana FONTES e Danielle Carusi MACHADO (2007), que analisou dados da PNAD (IBGE) de 1992 a 2005 e constataram a dificuldade de acesso a serviços de apoio à participação de mulheres com filhos no mercado de trabalho. O conflito relatado por essas pesquisadoras é mais uma vez constatado, agora em uma amostra focada em bairros de baixa renda da cidade de São Paulo. Por ter sido uma pesquisa específica para o tema, foi possível, também, constatar que, além da dificuldade de conciliar as responsabilidades familiares com a participação no mercado de trabalho, que já havia sido levantadas por estudos anteriores, ainda existe uma discriminação anterior à contratação de mães de crianças pequenas que faz com que as taxas de desemprego para essa população específica seja ainda mais elevada, especialmente porque 
os empregadores supõem que essas mulheres incorrerão em maiores taxas de absenteísmo do que o restante da população. Já para os pais, o efeito é inverso: alguns empregadores preferem contratar pais por considerá-los mais responsáveis.

A dificuldade enfrentada por essas mães para participar do mercado de rabalho tem impacto direto na renda familiar e, consequentemente, na pobreza, pois uma família com dois provedores de renda tem menor probabilidade de ser pobre do que com somente um (CEPAL, 2009). Além disso, a dificuldade para garantir o cuidado para as crianças e ser capaz de gerar renda aumenta o custo em termos de estresse e qualidade de vida para as mães, algo que afeta muito menos os pais. A prescrição de política pública mais imediata que surge desse estudo é a necessidade de um aumento dramático da corresponsabilidade do Estado com a provisão de cuidados com crianças e aumento dessa provisão em tempo integral. Essa política, por si só, já teria um efeito na redução da discriminação por parte dos empregadores ao longo do tempo.

\section{Agradecimentos}

As autoras agradecem o suporte financeiro da FAPESP que permitiu a coleta dos dados utilizados nessa pesquisa (processo 12/09609-5). Merike Blofield agradece o suporte financeiro através de bolsa para pesquisador estrangeiro, também concedida pela FAPESP (processo 2011/16171-3). Regina Madalozzo agradece a Bolsa de Produtividade de Pesquisa do CNPq (processo 302885/2012-9). Ambas as pesquisadoras agradecem a Matheus Hector Garcia pelo auxílio e disponibilidade na confecção dos gráficos.

\section{Referências}

ARNOLD, Jens; JALLES, João. "Dividing the Pie in Brazil: Income Distribution, Social Policies and the New MiddleClass". OECD Economics Department Working Papers, n. 1105 , 2014. OECD Publishing. Disponível em: http://dx.doi.org/ 10.1787/5jzb6w1 rt99p-en.

BANCO Mundial. Databank, 2013. Disponível em: http:// data.worldbank.org/indicator/SL.TLF.CACT.FE.ZS?locations $=$ BR. Acesso em: 05/12/2016.

BARKER, Garry; CONTRERAS, Juan Manuel; HEILMAN, Brian; SINGH, Ajay; VERMA, Ravi. "Evolving Men: Initial Results from the International Men and Gender Equality Survey (IMAGES)". Men, Boys and Gender Equality. Washington: International Center for Research on Women (ICRW); Rio de Janeiro: Instituto Promundo, jan. 2011 . Disponível em: http:/ /menandboys.ids.ac.uk/files/evolving-men-initial-resultsinternational-men-and-gender-equality-survey-images-0. 
BERLINSKI, Samuel; GALLIANI, Sebastian e McEWAN, Patrick. "Preschool and Maternal Labor Market Outomces Evidence form a Regression Discontinuity Design". IFS Working Paper W9/5, Institute for Fiscal Studies, 2008.

BLOFIELD, Merike. Care Work and Class: Domestic Workers' Struggle for Equal Rights in Latin America. College Park: Pennsylvania State University Press, 2012.

BRUSCHINI, Maria Cristina Aranha e RICOLDI, Arlene Martinez. "Família e Trabalho: difícil conciliação para mães trabaIhadoras de baixa renda". Cadernos de Pesquisa, v. 39, n. 136, p. 93-123, 2009.

BRUSCHINI, Cristina. "Trabalho doméstico: inatividade econômica ou trabalho não remunerado?". Revista Brasileira de Estudos Populacionais, v. 23, n. 2, p. 331-353, 2006.

BUDIG, Michelle; ENGLAND, Paula. "The Wage Penalty for Motherhood". American Sociological Review, v. 66, p. 204225, 2002

CHIODA, Laura. Work \& family: Latin America and Caribbean Women in search of new balance Conference Edition. Washington: World Bank, 2011.

CHRISTIANSEN, Shawn L.; PALKOVITZ, Rob. "Why the 'Good Provider' Role Still Matters: Providing as a Form of Paternal Involvement". Journal of Family Issues, v. 22, n. 1, p. 84106, 2001.

CONTRERAS, Dante; SEPULVEDA, Paulina; CABRERA, Soledad. The Effects of Lengthening the School Day on Female Labor Supply: Evidence from a Quasi-Experiment in Chile. Departamento de Economía, Facultad Economía e Negocios, Universidad de Chile, 2010. (Serie Documento de Trabajo)

DE OLIVEIRA, Pedro Rodrigues; SCORZAFAVE, Luiz Guilherme; PAZELLO, Elaine Toldo. "Desemprego e inatividade nas metropoles brasileiras: As diferencas entre homens e mulheres". Nova Economia, v. 19, n. 2, p. 291-324, 2009.

DIEESE. "O emprego doméstico no Brasil". Estudos e Pesquisas, n. 68, 2013. Disponível em: http://www.dieese.org.br/ estudosetorial/2013/estPesq68empregoDomestico.pdf. Acesso em: 05/12/2016.

ESPING-ANDERSEN, Gøsta. The Incomplete Revolution: Adapting to Women's New Roles. Cambridge: The Polity Press, 2009.

FERREIRA, Aurelio Buarque de Holanda. Novo Dicionário Aurelio da Língua Portuguesa, 2.ed. Rio de Janeiro: Nova Fronteira, 1986.

GANGLE, Markus; ZIEFLE, Andrea. "Motherhood, Labor Force Behavior, and Women's Careers: An Empirical Assessment of the Wage Penalty for Motherhood in Britain, Germany, and the United States". Demography, v. 46, p. 341-369, 2009. 
GUEDES, Maria Eunice Figueiredo. "Gênero, o que é isso?". Psicologia: Ciência e Profissão, v. 15, n. 1-3, p. 4-11, 1995.

HALLMAN, Kelly; QUISUMBING, Agnes R.; RUEL, Marie; LA BRIÈRE, Benedicte de. "Mothers' work and childcare: Findings from the urban slums of Guatemala City". Economic Development and Cultural Change, v. 53, n. 4, p. 855$885,2005$.

HEYMANN, Jody. Forgotten Families Ending the Growing Crisis Confronting Children and Working Parents in the Global Economy. Oxford: Oxford University Press, 2006.

HIRATA, Helena; GUIMARÃES, Nadya Araujo Guimarães (Eds.). Cuidado e cuidadoras: as várias faces do trabalho do Care. São Paulo: Atlas, 2012.

HIRATA, Helena. "Gênero, classe e raça: intereseccionalidade e consubstancialidade das relações sociais". Tempo Social, v. 26, n. 1, p. 61-73, 2016.

IBGE. Instituto Brasileiro de Geografia e Estatística. Disponível em: www.ibge.gov.br.

IBGE. Instituto Brasileiro de Geografia e Estatística. Pesquisa Nacional por Amostra de Domicílios, 2013. Disponível em: www.ibge.gov.br.

KELLY, Kimberly and GRANT, Linda. "Penalties and premiums: The impact of gender, marriage, and parenthood on faculty salaries in science, engineering and mathematics (SEM) and non-SEM fields". Social Studies of Science, v. 42, Issue 6, p. 869-896, 2012.

KILLERWALD, Alexandra. "A Reconsideration of the Fatherhood Premium: Marriage, Coresidence, Biology, and Fathers' Wages". American Sociological Review, v. 78, Issue 1, p. 96-116, 2013.

MADALOZZO, Regina; MARTINS, Sérgio Ricardo; SHIRATORI, Ludmila. "Participação no Mercado de Trabalho e no Trabalho Doméstico: homens e mulheres têm condições iguais?". Revista Estudos Feministas, v. 18, n. 2, p. 547 566, 2010.

MARSIGLIO, William; AMATO, Paul R.; DAY, Randal D.; LAMB, Michael E. "Scholarship on Fatherhood in the 1990s and Beyond". Journal of Marriage and Family, v. 62, p. 1173 1191, 2000.

MEDRANO, Patricia. Public Day Care and Female Labor Force Participation: Evidence from Chile. Santiago de Chile: Facultad de Economía y Negocios Universidad de Chile, 2009. [Serie documentos de trabajo 306]

NERI, Marcelo Cortes. Os emergentes dos emergentes: reflexões e ações para a nova classe média brasileira. Rio de Janeiro: Fundação Getulio Vargas, 2011.

QUISUMBING, Agnes R. Household Decisions, Gender, and Development: A Synthesis of Recent Research. 
Washington: International Food Policy Research Institute, 2003.

ROSA, Waldemir. "Sexo e cor: categorias de controle social e reprodução das desigualdades socioeconômicas no Brasil". Revista Estudos Feministas, v. 17, n. 3, p. 889-899, 2009.

SOARES, Cristiane; SABOIA, Ana Lucia. Tempo, trabalho e afazeres domésticos: um estudo com base nos dados da Pesquisa Nacional por Amostra de Domicílios de 2001 e 2005. Texto para Discussão do IBGE - Diretoria de Pesquisas, n. 21. Ministério do Planejamento, Orçamento e Gestão. Instituto Brasileiro de Geografia e Estatística IBGE. Diretoria de Pesquisas. Coordenação de População e Indicadores Sociais. Rio de Janeiro, 2007. Disponível em: http://www.ibge.com.br/home/estatistica/populacao/ tempo_trabalho_afdom_pnad2001_2005.pdf. Acesso em: 06/05/2016.

SORJ, Bila. "Arenas de cuidado nas interseções entre gênero e classe social no Brasil". Cadernos de Pesquisa, São Paulo, v. 43, n. 149, mai./ago. 2013.

SORJ, Bila; FONTES, Adriana; MACHADO, Danielle Carusi. "Políticas e práticas de conciliação entre família e trabalho no Brasil". Cadernos de Pesquisa, v. 37, n. 132, p. 573-594, 2007.

STÄHLI, Michèle Ernst; LE GOFF, René Levy; WIDMER, Eric. 'Wishes or Constraints? Mothers' Labour Force Participation and its Motivation in Switzerland". European Sociological Review, v. 25, n. 3, p. 333-348, 2009.

UNITED Nations Development Programme and the International Labour Organization (PNUD-OIT). Trabajo $y$ Família: Hacia nuevas formas de conciliación con corresponsabilidad social. Geneva: UNDP-ILO, 2009.

[Recebido em 22/02/2015, reapresentado em 10/05/2016 e aceito para publicação em 23/06/2016]

How low-income families in São Paulo reconcile work and family?

Abstract: While women's labor force participation rates have increased in Brazil, unpaid care responsibilities remain unequally divided between mothers and fathers. Based on an original, representative survey of 700 mothers and fathers of young children in low-income neighborhoods in São Paulo, this article examines the gender differences in labor force participation, and its relationship to access to child care and family caregiving responsibilities. The analysis concludes that work-family conflicts and responsibility for children fall disproportionately on mothers, regardless of whether they prefer to remain active in the labor market or not. Policies that promote paternal and state co-responsibility are essential to reduce this conflict.

Key words: family; labor market; gender; low-income families 
Regina Madalozzo (reginam@insper.edu.br). PhD em Economia pela University of Illinois at Urbana-Champaign. Professora Associada no Insper, onde atua desde 2002.

Merike Blofield (m.blofield@miami.edu). University of Miami, Estados Unidos da América do Norte. É professora associada do departamento de Ciências Políticas da University of Miami. Nativa da Finlância, ela já residiu no Canadá, Chile, Brasil, Argentina e nos Estados Unidos. 